\title{
Original article (full paper) \\ The relationship between physical fitness and shooting accuracy of professional basketball players
}

\author{
Haris Pojskić \\ Vlatko Šeparović \\ Melika Muratović \\ Edin Užičanin \\ University of Tuzla, Bosnia and Herzegovina
}

\begin{abstract}
The aim of this study was to examine the relationships among physical fitness of professional Bosnian basketball players $(n=38)$ and shooting accuracy during one basketball season. A related, secondary aim was to examine relationships between basketball shooting assessments and competitive shooting accuracy during game play. Physical fitness components included: muscular endurance and aerobic endurance, lower and upper-body power, speed, agility, anaerobic capacity and anaerobic power. The specific basketball shooting accuracy was assessed by stationary and dynamic shooting assessments. Competitive shooting accuracy was represented by data collected during one basketball season for each player (free throw, field goal, and three-point \%). Results of the regression analyses showed that there were significant positive relationships among shooting assessments and competitive shooting accuracy during game play. The relationship was stronger when the dynamic shooting tests were applied compared to the stationary tests. However, few or weak relationships existed among physical fitness components and competitive shooting accuracy. Only the power tests showed to be good predictors for shooting over longer distances. The findings support the inclusion of the dynamic basketball shooting accuracy tests in regular basketball assessment procedures as a valuable testing instrument.
\end{abstract}

Keywords: shooting skill tests, speed, agility, aerobic power, anaerobic capacities, fatigue index

Resumo- - "A relação entre aptidão física e precisão de arremesso dos jogadores profissionais de basquetebol." $\mathrm{O}$ objetivo do presente estudo foi identificar a relação entre a condição física de basquetebolistas profissionais bósnios $(n=38)$ na precisão de arremesso no decorrer de uma temporada competitiva. Adicionalmente, pretendeu-se verificar a relação entre a avaliação específica e a precisão de arremessos durante os jogos. As variáveis de condição física foram as seguintes: resistência de força, resistência aeróbia, potência dos membros inferiores e superiores, velocidade, agilidade, capacidade e potência anaeróbia. A avaliação específica do arremesso foi testada através da utilização de arremessos estáticos e dinâmicos. A precisão dos arremessos durante os jogos foi realizada no decorrer da temporada competitiva mediante análise das seguintes variáveis: lance-livre, arremessos de quadra, e percentagem de arremessos de três pontos. As análises de regressão indicaram a existência de uma relação positiva entre as avaliações específicas dos arremessos e a precisão durante os jogos, a qual foi mais forte nas situações de arremessos dinâmicos comparados aos estáticos. Contudo, as relações existentes entre as variáveis de condição física e a precisão de arremesso durante os jogos foram menores e pouco significativas. Apenas os testes de potência mostraram ser bons preditores para os arremessos efetuados a longas distâncias. Os resultados obtidos apoiam a inclusão de testes de avaliação da precisão de arremessosrealizados de forma dinâmica em procedimentos regulares de avaliação no basquetebol, constituindo-se como instrumentos valiosos para ocontrole do rendimento.

Palavras-chave: testes de precisão de arremessos, velocidade, agilidade, potência aeróbia, capacidades anaeróbias, índice de fadiga

Resumen- "La relación entre la aptitud física y precisión de tiro de los jugadores profesionales de baloncesto." El objetivo de este estudio fue examinar la relación entre la condición física de los jugadores profesionales de baloncesto de Bosnia $(n=38)$ y la precisión de tiro durante una temporada de baloncesto. Paralelamente, el objetivo secundario fue examinar las relaciones entre las evaluaciones de lanzamiento de baloncesto y la precisión de tiro durante el partido. Los componentes de la aptitud física incluían: la resistencia muscular y la resistencia aeróbica, la potencia de los miembros inferiores y superiores del cuerpo, la velocidad, la agilidad, la capacidad anaeróbica y la potencia anaeróbica. La precisión específica de tiro de baloncesto se evaluó mediante lanzamiento estático y evaluaciones de tiro en movimiento. La precisión de tiro en competición estuvo representada por los datos recogidos durante una temporada de baloncesto para cada jugador (tiro libre, tiro de campo y triple \%). Posteriores análisis de los resultados mostraron que había una 
significativa relación positiva entre las evaluaciones de tiro y la precisión de tiro durante el partido. La relación era más fuerte cuando las pruebas de tiro en movimiento se compararon con las pruebas de tiro estático. Sin embargo, existían pocas o débiles relaciones entre los componentes de la aptitud física y la precisión de tiro en competición. Sólo las pruebas de potencia mostraron ser buenas predictoras para lanzamientos de mayor distancia. Los resultados apoyan la inclusión de los entrenamientos de precisión de tiro en movimiento en los procedimientos habituales de evaluación de baloncesto, como un valioso instrumento de prueba.

Palabras clave: pruebas de habilidad de disparo, velocidad, agilidad, potencia aeróbica, capacidades anaeróbicas, índice de fatiga

\section{Introduction}

Basketball has been described as an intermittent sport, being physically very demanding, requiring players to frequently repeat bouts of intense actions (sprinting, shuffling, jumping) with jogging, walking or short periods of recovery (Ben Abdelkrim, El Fazaa, \& El Ati, 2006; McInnes, Carlson, Jones, \& McKenna, 1995). It involves both aerobic and anaerobic energetic processes (Narazaki, Berg, \& Stergiou, 2008; Tessitore et al., 2006). Consequently, in order to play successfully, basketball players must be physically well prepared by having optimally developed levels of explosive power, agility, anaerobic power and anaerobic capacities (Apostolidis, Nassis, Bolatoglou, \& Geladas, 2004; Ben Abdelkrim, Chaouachi, Chamari, Chtara, \& Castagna, 2010; Delextrat \& Cohen, 2008; Hoffman, Tenenbaum, Maresh, \& Kraemer, 1996). Besides a high level of physical fitness, basketball players also need to have the improved technical skills that have shown to have a significant correlation with players' physical fitness (Apostolidis et al., 2004).

One of the main skills that determine successful playing of basketball is shooting accuracy (Erčulj \& Supej, 2006). Some previous studies have shown the importance of free throws, field goals and three-point shot accuracy in distinguishing winning and losing basketball teams (Pojskić, Šeparović, \& Užičanin, 2009; Trninić, Dizdar, \& Lukšić, 2002). In order to achieve a high shooting percentage and victory, every team has to have players who can accurately shoot in all periods of the game and under different physiological or psychological pressures. Consequently, it can be said that shooting accuracy is one of the most important skills in basketball (Erčulj \& Supej, 2006; Pojskić, Šeparović, \& Užičanin, 2011) which poses the question of its determinants.

Unfortunately, to our knowledge there are very few studies which have looked into the relationship between basketball shooting accuracy and other physical fitness components. One such study, however, was done by Tang and Shung (2005) who reported the importance of the elbow extensor isokinetic strength in long distance shooting accuracy. Also, there are a lack of studies that have investigated the relationship between basketball players' physical fitness and their shooting accuracy in competitive conditions, as well as the relationship between basketball shooting skill tests and competitive accuracy.

The most commonly used test to evaluate the basketball shooting skill is the AAPHERD basketball test (Strand \& Wilson, 1993), which is designed for middle school and high school students, but not for competitors. In that regard, knowing the fact that a key factor for successful basketball playing is accurately shooting after high intensity movements with high fatigue impact (Erčulj \& Supej, 2006), we wanted to use newly designed basketball shooting tests that are more appropriate for competitors (Pojskić et al., 2011) and to relate them with players' physical fitness and competitive accuracy. These tests have been designed to simulate more realistic situations, because they require a player to sprint, receive the ball, turn to the basket and perform a jump shot. Such time restricted tests in which a player needs to shoot as many balls as possible after intensive movements with a simulation of the usage of a teammate's screen, create physiologically very demanding conditions and a high fatigue impact for the player.

It is because of the lack of investigations into the association between physical fitness and basketball shooting accuracy that we initiated the present study and raised the research question: is there a relationship between basketball players' physical fitness, basketball shooting skill tests and competitive shooting accuracy? Knowing this relationship may have crucial practical value in creating basketball strength and conditioning programs as well as in detecting talented basketball shooters.

Therefore, the first aim of this study was to determine the correlation between physical fitness parameters and competitive basketball shooting accuracy registered during one competitive season; the second aim was to investigate the possible relationship between the newly designed basketball shooting skill tests and competitive shooting accuracy. According to factors of success in basketball mentioned in previous studies, we hypothesized a positive correlation between speed, agility, explosive power tests, aerobic power, anaerobic capacities and the parameters of competitive shooting accuracy, as well as a positive association between the basketball shooting skill tests, and the parameters of competitive shooting accuracy.

\section{Methods}

\section{Participants}

Thirty-eight healthy basketball players (point guards, shooting guards and small forwards) from four teams of the Bosnian Premier League voluntarily participated in the study. All players had played at national level and they had to play at least 16 games and at least 10 minutes per game in order to be included in the research. All of them were healthy without any history of neuromuscular diseases or reported injury in the previous 
Table 1. Mean, standard deviation (SD) and range for age and anthropometric characteristics of the perimeter basketball players $(n=38)$.

\begin{tabular}{lccc}
\hline Variables & Mean & SD & Range \\
\hline Age (years) & 18.97 & 2.862 & $17-28$ \\
Body Height $(\mathrm{cm})$ & 185.35 & 6.73 & $171.0-192.3$ \\
Body Weight $(\mathrm{kg})$ & 78.66 & 10.35 & $61.0-93.8$ \\
Body Fat $(\%)$ & 12.39 & 1.74 & $6.1-17.5$ \\
Fat Free Mass $(\mathrm{kg})$ & 68.63 & 7.26 & $57.2-80.4$ \\
\hline
\end{tabular}

six months. At the time of research they had $7.5 \pm 2.6$ years of competitive experience. Their anthropometric characteristics are presented in Table 1. According to their clubs' head coaches, they trained 10 hours a week ( 5 sessions of 2 hours each) on court, improving technical and tactical skills, and 4.5 hours a week ( 3 sessions of 1.5 hours each) off court in the gym improving their strength, power and endurance, with a basketball game played every Saturday or Sunday. They were asked to refrain from the heavy training, tobacco, alcohol and caffeine use and to avoid sleep deprivation for at least two days prior the testing sessions. The subjects were allowed to consume a light meal at least three hours prior the beginning of the testing sessions. In order to stay properly hydrated, the players were asked not to drink a large amount at once, but to drink water often, in small amounts during the testing sessions. Players were told they were free to withdraw from the study at any time without penalty. Written informed consent was received from all players and parents after a detailed verbal and written explanation of the experimental design, the purpose of the study, testing protocols, research benefits and potential risks of the study. The study was approved by the Institutional Review Board of the Tuzla University (October, 22 ${ }^{\text {nd }}, 2009 ; N^{\circ}$ : 03.-8180-12.1/09) and conformed to the principles of the Declaration of Helsinki on human experimentation (WMADH, 2000).

\section{Experimental procedures}

The players' physical fitness and specific shooting accuracy were tested immediately after the season finished, during a two-week break. The assessment sessions were conducted over six separate days, between 9 and 11 a.m., with 48 hours between the sessions. To minimize variation in climatic and other conditions, all measurements were performed in a sport hall on a parquet floor except the Repeated Anaerobic Sprint Test (RAST) test which was performed in a track and field stadium. All players were familiar with the testing procedures because they routinely performed the tests during individual strength and conditioning programs. All of them were encouraged to make as much effort as possible during all tests. A ten-minute general warm-up (jogging), seven minutes of active dynamic stretching and activities to increase intensity (sprints and jumps) were performed before physical fitness testing. Twelve minutes of specific basketball shooting drills were additionally included before testing basketball shooting accuracy.

Players from each team were randomly split into two groups with an equal number of players. During the first testing day, body composition was assessed for each player. After that they performed the warm-up and then a multistage shuttle run test that was used to estimate maximal oxygen consumption $\left(\mathrm{VO}_{2 \max }\right)$. On the second day motor abilities were assessed; one group of players was tested by countermovement jump, triple jump and seated medicine ball toss, while the second group was tested by a $20 \mathrm{~m}$ sprint test and agility $T$ test. The two groups then took the other set of tests. Sit ups and push ups were assessed three times during the last three testing days after assessing basketball shooting accuracy with randomized order of the first and the second group. On the third day the parameters of anaerobic capacities were assessed using the RAST. On the fourth, fifth and sixth days the specific shooting accuracy of free throws, field goals and three-point shots were tested in randomized order of the first and the second group.

Body height $(B H)$ was measured to the nearest $0.01 \mathrm{~m}$ with a portable stadiometer (Astra scale 27310, Gima, Italy). Body weight $(B W)$, body fat percentage (FAT\%) and fat free mass (FFM) were measured by a bioelectric body composition analyzer (Tanita TBF-300 increments $0.1 \%$; Tanita, Tokyo, Japan).

Vertical jump performance (CMJ - counter movement jump) was assessed according to the protocol described by Bosco, Luhtanen \& Komi (1983). Each player performed three maximal CMJ jumps, allowing three minutes of recovery in between. The highest score was used for analysis. The jumps were assessed using a portable device called the OptoJump System (Microgate, Bolzano, Italy). The test has demonstrated a high reliability coefficient of 0.98 (Markovic, Dizdar, Jukic, \& Cardinale, 2004).

Seated Medicine Ball Toss (SMBT). This test was used to assess upper-body power. The players were seated with their back and buttocks against a chair, holding a ball in their horizontally extended hands with the ball right above the initial line. A distance of the chair was adjusted for each player according to their hands' length. Their feet were resting on the floor. The players were asked to move the ball towards their chest and to throw the $1 \mathrm{~kg}$ medicine ball in a horizontal direction as far as possible using a 2-handed chest pass. They were not allowed to move the back of their chair. The test performance was measured with a measuring tape, as the distance from the initial line to the point where the ball fell. An assessor had to follow the ball flight and to observe the correct position where the ball made contact with the floor. They performed three trials, with the longest result used for analysis. The test has demonstrated a high reproducibility (van den Tillaar \& Marques, 2013)

Sit Ups (SU). This test was used to assess muscular strength and endurance in the abdominal wall. The players performed the test according to Diener, Golding, and Diener (1995). When the examiner signaled " $g o$," a timer was started and the players performed as many repetitions as possible in one minute. The examiner counted the number of correctly performed repetitions. The score was expressed as the number of repetitions in 60 seconds. They performed three trials on three different days, with the highest score used for analysis. The test-retest reliability has been reported to be very high $(\mathrm{ICC}=.98)$

Push Ups (PU). This test was used to assess upper body muscular strength and endurance. The players performed the test according to Hashim (2012). The maximum number of 
correct repetitions accomplished in 60 seconds was recorded. The players performed three trials on three different days, with the highest score used for analysis. The test-retest reliability has been reported to be very high $(\mathrm{ICC}=.93)$

Speed. The players performed three 20 -meter sprints on an indoor parquet floor with a three minute recovery between each. The best score was used for analysis. The players started from starting blocks individually set to the participants' characteristics. The $20 \mathrm{~m}$ dashes were timed with an automated timer (Speedtrap II, Brower Timing Systems, Draper, UT, USA). This timer utilized a pressure pad placed under the fingers of the sprinter's right hand in the starting position. The timing device started when the sprinter lifted their fingers off of the pressure pad, and stopped when the sprinter broke a single laser light beam projected across the track $20 \mathrm{~m}$ from the starting line. To avoid error, the laser beam was positioned so the height above the ground approximated the height of the players' waist. Once the athletes were prepared, they started on their own decision. The test high reliability (ICC $=.96)$ was reported by Lockie, Schultz, Callaghan, Jeffriess, \& Berry (2013).

Agility was measured using a standard agility T test (ATT). The test has demonstrated high reliability across trials with a reliability coefficient of .98 indicating that only one trial is necessary to obtain a true $T$-test score (Pauole, Madole, Garhammer, Lacourse, \& Rozenek, 2000). This test was administered using the protocol outlined by Semenick (1990). The players performed three $T$-tests on an indoor parquet floor with a three minute recovery between each test. The best score was used for analysis. The test time was also recorded with the automated timer (Speed trap II, Brower Timing Systems, Draper, UT, USA).

Maximal aerobic power (VO2max) was estimated using the 20m shuttle run test according to Leger and Gadoury (1989). The test-retest reliability coefficients are .89 for children and .95 for adult men and women.

Anaerobic capacity was assessed with the Running-based Anaerobic Sprint Test (RAST). The test was performed according to the protocol described by Zagatto, Beck, and Gobatto (2009). After completion of the test, the following variables were calculated: Maximal Power (MaxPOW), Average Power (AvePOW), Minimal Power (MinPOW), Fatigue Index (FI) and Relative Maximal Power (R-MaxPow). The variables were calculated by the following equations: Power $=$ Weight $(\mathrm{kg})$ $\times$ Distance $\left(\mathrm{m}^{2}\right) \div$ Time $\left(\mathrm{s}^{3}\right)$. Maximum power $=$ the highest value of six sprints, Minimum power $=$ the lowest value of six sprints, Average power $=$ sum of all six values $\div 6$, Fatigue Index $=($ Maximum power - Minimum power $) \div$ Total time for the 6 sprints, R-MaxPow $=$ Maximum power $/$ Body Weight, R-AvePow $=$ Average Power / Body Weight, R-Fatigue Index $=$ Fatigue Index / Body Weight. The test reliability $(r=.88)$ was reported by Zagatto et al. (2009).

\section{Basketball shooting accuracy tests}

The stationary free throw shooting test (S1P). After the war$\mathrm{m}$-up protocol, described in the testing procedures, every player performed three series of ten free-throw shots, with a 3-minute

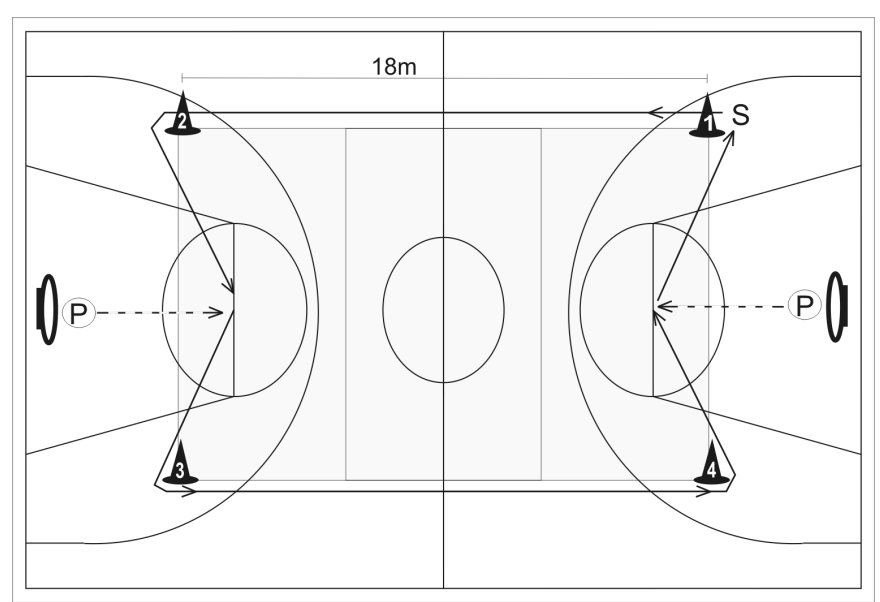

Figure 1. The dynamic 60-second free throw shooting test (S1P60). Legend. $\mathrm{P}=$ passer, $\mathrm{S}=$ shooter $/$ testee.

rest period between the series. Two players were positioned below the hoop and they passed the ball to the testee. After one player had completed ten shots, another came to the free throw line and performed the same task. The average percentage of the all three trials was used for analysis.

\section{The dynamic 60-second free throw shooting test S1P60)}

For easier organization of the testing we used volleyball court lines as illustrated in Figure 1. Each player performed five series of two free throws with sprinting between the series. Each series had to be completed in 12 seconds. Each player started the test with an 18-meter sprint (volleyball court sideline), made a turn around a cone and ran $4.6 \mathrm{~m}$ to the free throw line. After performing two free throws the player ran $4.6 \mathrm{~m}$ to another cone where he waited for a sound signal to start the next series. One tester used a stopwatch to measure 12 seconds, and to give a signal to the player. Another tester counted the number of free throws made. Two other players passed the balls to the testee. The players performed the three S1P60 tests with a five minute recovery between each. The average percentage of all three trials was used for analysis.

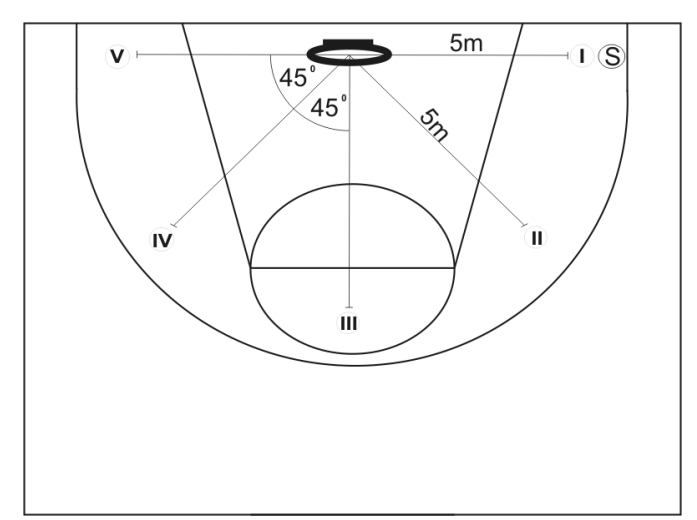

Figure 2. The stationary two-point shooting test (S2P) Legend. $\mathrm{S}=$ shooter/testee. 


\section{The stationary two-point shooting test (S2P)}

Each player, in one of three series, performed two jump shots from five different positions, i.e. ten shots in total (Figure 2). The player's starting position was on the right wing; at position number I. Shooting positions were set at a distance of five meters from the vertical projection of the hoop's centre on the floor. There was no time limit for the shots. Two other players caught the ball and passed it back to the testee. There was a three-minute rest period between each shooting series. The average percentage of all three trials was used for analysis.

\section{The dynamic 60-second two-point shooting test (S2P60)}

The player's starting position was below the hoop, next to cone number one (Figure 3). After the tester sounded a signal, the player ran $5 \mathrm{~m}$ to the wing (cone 2 ) where he received the ball from the passer (P1) and performed a jump shot. Then he ran again around cone 1 towards cone 3 where he received the ball again from the other passer (P1) and performed another jump shot. After completing the same procedure for cones 4,5 and 6 he continued with the test by running in the opposite direction towards the fifth cone, fourth cone and so on, depending on the amount of time still available. The test finished after sixty seconds. The players were encouraged to run as fast as they could and to perform as many shots as they could. One rebounder and two passers were needed for the testing procedure. Rebounder (R) caught all shots made and passed the ball to passer 2. Passer 2 always received the ball from the rebounder and passed it to passer 1. Passer 1 always passed the ball to the shooter. The players performed the three S2P60 tests with a five minute recovery between each. The average percentage of all three trials was used for analysis.

\section{The stationary three-point shooting test (S3P)}

Each player, in one of three series, performed two jump shots from five different positions, i.e. ten shots in total (Figure 4). The player's starting position was on the right wing; at position

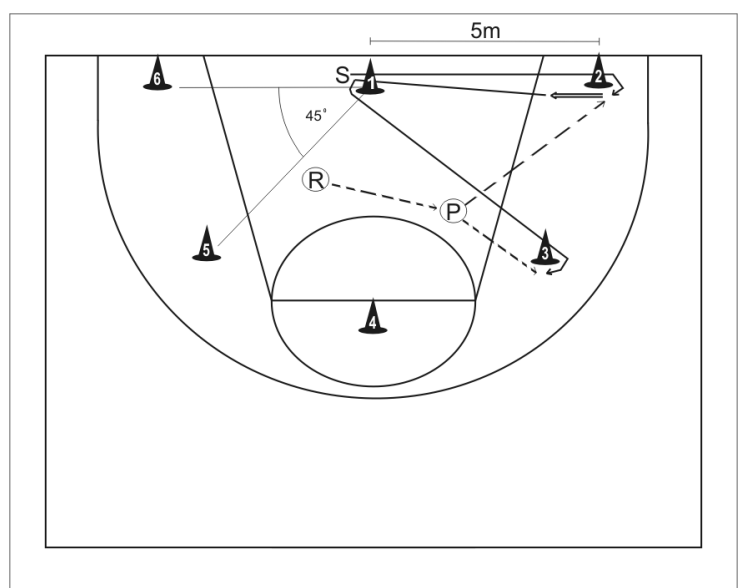

Figure 3. The dynamic 60-second two-point shooting test (S2P60) Legend. $\mathrm{R}=$ rebounder, $\mathrm{P}=$ passer, $\mathrm{S}=$ shooter/testee.

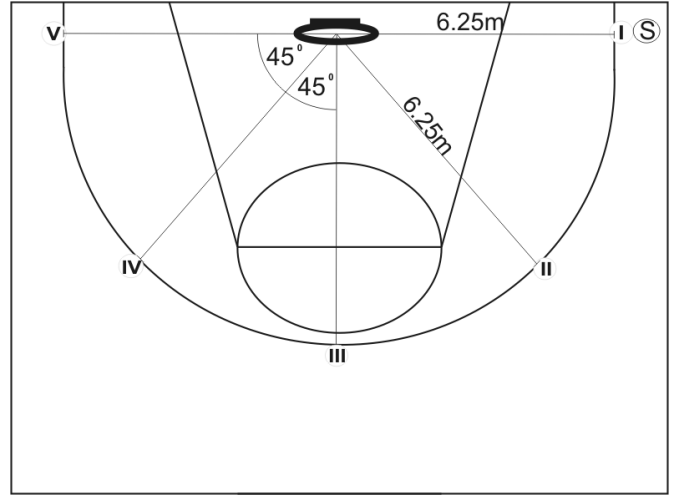

Figure 4. The stationary three-point shooting test (S3P) Legend. $\mathrm{S}=$ shooter/testee.

number I. Shooting positions were set at a distance of $6.25 \mathrm{~m}$ from the vertical projection of the hoop's centre on the floor. There was no time limit for the shots. Two other players caught the ball and passed it back to the testee. There was a threeminute rest period between each shooting series. The average percentage of all three trials was used for analysis.

\section{The dynamic 60-second three-point shooting test (S3P60)}

The player's starting position was below the hoop, next to cone number one (Figure 5). After the sound signal, he ran $6.25 \mathrm{~m}$ to the wing (cone 2) where he received the ball from the passer (P1) and performed jump shot. Then he ran again around cone 1 towards cone 3 where he received the ball again from the other passer (P1) and performed another jump shot. After completing the same procedure for cones 4,5 and 6 , he continued with the test by running in the opposite direction towards the fifth cone, fourth cone and so on depending on the amount of time still available. The test finished after sixty seconds. Players were encouraged to run as fast as they could and to perform as many shots as they could. One rebounder and two passers were needed for the testing procedure. The rebounder $(\mathrm{R})$ caught all shots made and passed the ball to passer 2. Passer 2 always received the ball from the rebounder and passed it to passer 1 . Passer 1 always passed the

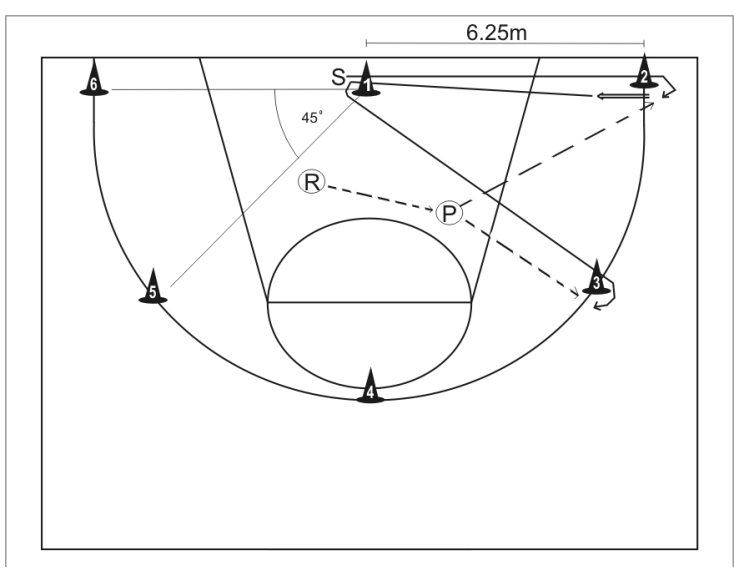

Figure 5. The dynamic 60-second three-point shooting test (S3P60) Legend. $\mathrm{R}=$ rebounder, $\mathrm{P}=$ passer, $\mathrm{S}=$ shooter/testee. 
ball to the testee. The players performed the three S3P60 tests with a five minute recovery between each. The average percentage of all three trials was used for analysis. All the shooting accuracy tests show high reproducibility (Pojskic et al., 2011).

The competitive shooting accuracy was recorded during the whole season by assistant coaches who used a specially designed statistical record form for each player. From the form we extracted the number of attempted and successful shots for free throws (FT\%), field goals (FG\%) and three point shots (3P\%), and we calculated the shooting percentage for each distance. In the analyses we included a field goal only when attempted outside the paint area and performed by a jump shot. For the purpose of the study we calculated the average percentage from all games for each player. The total number of analyzed games was eighty-eight with twenty-two games per team.

\section{Statistical analyses}

Descriptive statistics (mean, standard deviation, and range) were calculated for each variable. Data sets were checked for normality using the Kolmogorov-Smirnov test and by the visual observation of normality plots. Multiple regression analysis (enter method) was used to examine: 1) the overall relationship between physical fitness and competitive shooting accuracy, 2) the overall relationship between basketball shooting skill tests and competitive shooting accuracy, 3) the contribution of each predictor (independent) variables to the relationship. Significance for all statistical tests was set at $p \leq .05$. All statistical analyses were completed with the SPSS software statistical package (SPSS Inc., Chicago, IL; Version 14.0).

\section{Results}

The descriptive statistics were calculated for all tested variables including age and anthropometric characteristics. Table 2 shows the mean value, standard deviation and range. The test-retest reliability and variability data for all tests involving three trials was calculated and is presented in Table 2 as well using the Interclass Correlation Coefficient (ICC) and Coefficient of Variation (CV). The ICC for fitness variables was fairly high, ranging from .89 to .92 , and $\mathrm{CV}$ ranged from $2.87 \%$ to $25 \%$. Lower reproducibility and higher variability is observed for all basketball shooting tests as well as for all competitive shooting parameters (ICC ranged from .71 - .92; CV ranged from $12.63 \%$ to $42.94 \%$ ).

Table 2. Mean, standard deviation (SD), range, coefficient of variation (CV\%) and interclass correlation coefficient (ICC) for physical performance measurement and basketball shooting accuracy of the perimeter basketball players $(n=38)$.

\begin{tabular}{|c|c|c|c|c|c|}
\hline Variables & Mean & SD & Range & $\mathrm{CV}(\%)$ & ICC \\
\hline Counter Movement Jump (cm) & 38.48 & 3.45 & $29.4-53.6$ & 8.97 & .92 \\
\hline Seated Medicine Ball Toss (m) & 10.01 & 1.15 & $8.2-12.6$ & 11.49 & .89 \\
\hline Sit Ups (number of repetitions in 60 seconds) & 54.34 & 5.29 & $53-66$ & 9.74 & .91 \\
\hline Push Ups (number of repetitions) & 42.21 & 4.44 & $35-58$ & 10.52 & .90 \\
\hline $20 \mathrm{~m}$ - Sprint (s) & 3.14 & .090 & $2.95-3.38$ & 2.87 & .91 \\
\hline Agility T Test (s) & 10.48 & .409 & $9.74-11.46$ & 3.90 & .89 \\
\hline $\operatorname{VO} 2 \max \left(\mathrm{ml} \mathrm{x} \mathrm{kg}{ }^{-1} \times \mathrm{min}^{-1}\right)$ & 63.67 & 6.79 & $40.84-76.41$ & 10.66 & - \\
\hline RAST - Maximal Power (Watts) & 761.21 & 124.80 & $572.5-998.8$ & 16.39 & - \\
\hline RAST - Minimum Power (Watts) & 494.46 & 96.91 & $365.7-750.1$ & 19.60 & - \\
\hline RAST - Average Power (Watts) & 619.53 & 99.40 & $451.7-839.1$ & 16.04 & - \\
\hline RAST - Relative Maximal Power (Watts/kg) & 9.68 & .93 & $7.64-11.42$ & 9.61 & - \\
\hline RAST- Relative Average Power (Watts/kg) & 7.88 & .80 & $6.31-9.70$ & 10.15 & - \\
\hline Fatigue Index (Watts/s) & 8.21 & 1.44 & $4.68-15.33$ & 17.54 & - \\
\hline Relative Fatigue Index (Watts/s/kg) & .104 & .026 & $.067-.175$ & 25.00 & - \\
\hline S1P $(\%)$ & 81.22 & 10.26 & $56.67-96.67$ & 12.63 & .92 \\
\hline S1P60 (\%) & 66.66 & 12.10 & $40.00-86.67$ & 18.15 & .82 \\
\hline S2P (\%) & 63.25 & 11.76 & $30.00-87.00$ & 18.59 & .82 \\
\hline S2P60 (\%) & 52.83 & 12.58 & $30.30-77.41$ & 23.81 & .75 \\
\hline S3P (\%) & 49.21 & 15.96 & $20.00-80.00$ & 32.43 & .85 \\
\hline S3P60 (\%) & 42.00 & 13.20 & $18.75-68.75$ & 31.43 & .81 \\
\hline FT $(\%)$ & 66.61 & 13.86 & $25.00-87.50$ & 20.81 & .82 \\
\hline FG (\%) & 46.74 & 16.47 & $20.00-83.00$ & 35.24 & .77 \\
\hline $3 \mathrm{P}(\%)$ & 36.21 & 15.55 & $9.09-77.77$ & 42.94 & .71 \\
\hline
\end{tabular}

Legend: S1P = percentage of the stationary free throw shooting test; S1P60 = percentage of the dynamic 60-second free throw shooting test; $\mathrm{S} 2 \mathrm{P}=$ percentage of the stationary two-point shooting test; S2P60 = percentage of the dynamic 60 -second two-point shooting test; $\mathrm{S} 3 \mathrm{P}=$ percentage of the stationary three-point shooting test; S3P60 = percentage of the dynamic 60-second three-point shooting test; FT = free throw percentage during competitive season; $\mathrm{FG}=$ field goal percentage during competitive season; $3 \mathrm{P}=$ three points field goal percentage during competitive season. 
Table 3. The relationship between physical fitness, basketball shooting skill tests and competitive shooting accuracy for $n=38$.

\begin{tabular}{|c|c|c|c|c|c|c|}
\hline \multirow{3}{*}{ Independent predictors } & \multicolumn{6}{|c|}{$\begin{array}{c}\text { Dependent variables } \\
\text { (Competitive shooting accuracy) }\end{array}$} \\
\hline & \multicolumn{2}{|c|}{ FT $\%$} & \multicolumn{2}{|c|}{$\mathrm{FG} \%$} & \multicolumn{2}{|c|}{$3 \mathrm{P} \%$} \\
\hline & $\beta$ & $p$ value & $\beta$ & $p$ value & $\beta$ & $p$ value \\
\hline$\overline{\mathrm{CMJ}}$ & -.652 & .717 & .142 & .935 & .357 & $.037 * *$ \\
\hline SMBT & .078 & .795 & .137 & .639 & .376 & $.044 * *$ \\
\hline SIT UPS & -.091 & .695 & .066 & .763 & .154 & .508 \\
\hline PUSH UPS & -.236 & .359 & -.082 & .743 & -.182 & .466 \\
\hline $20 \mathrm{~m}$-SPRINT & -.341 & .285 & -.261 & .436 & -.047 & .876 \\
\hline ATT & -.006 & .981 & -.211 & .346 & -.204 & .362 \\
\hline $\mathrm{VO} 2 \max$ & .314 & .230 & -.166 & .492 & -.041 & .872 \\
\hline R-AvePow & -.894 & .216 & .396 & $.039 * *$ & .351 & .625 \\
\hline R-Fatigue Index & -.425 & .367 & -.460 & .308 & -.264 & .578 \\
\hline S1P $(\%)$ & .471 & $.041 * *$ & - & - & - & - \\
\hline S1P60 (\%) & .496 & $.023 * *$ & - & - & - & - \\
\hline S2P (\%) & - & - & .176 & .437 & - & - \\
\hline S2P60 (\%) & - & - & .339 & $.037 * *$ & - & - \\
\hline S3P (\%) & - & - & - & - & .377 & .087 \\
\hline S3P60 (\%) & - & - & - & - & .375 & $.022 * *$ \\
\hline Model summary & \multicolumn{2}{|c|}{$R^{2}=.51 ; p=.011^{*}$} & \multicolumn{2}{|c|}{$R^{2}=.27 ; p=.031^{*}$} & \multicolumn{2}{|c|}{$R^{2}=.24 ; p=.027^{*}$} \\
\hline
\end{tabular}

* Statistically significant the overall relationship between the predictor variables and dependent variable $(p<.05)$

** Statistically significant contribution of a particular predictor variable to the overall relationship $(p<.05)$

Legend: $\mathrm{R}^{2}=$ The squared multiple correlation coefficient; $\beta=$ Standardized Coefficient; CMJ = Countermovement Jump; SMBT = Seated Medicine Ball Toss; ATT - Agility T Test; VO2max = Maximal aerobic power estimated using the $20 \mathrm{~m}$ shuttle run test; R-Ave Pow = Relative Average Power achieved using Repeated Anaerobic Sprint Test (RAST); R-FI = Fatigue Index estimated using RAST; S1P = the stationary free throw shooting test; $\mathrm{S} 1 \mathrm{P} 60=$ the dynamic 60 -second free throw shooting test; $\mathrm{S} 2 \mathrm{P}=$ the stationary two-point shooting test; $\mathrm{S} 2 \mathrm{P} 60=$ the dynamic 60 -second two-point shooting test; $\mathrm{S} 3 \mathrm{P}=$ the stationary three-point shooting test; $\mathrm{S} 3 \mathrm{P} 60=$ the dynamic 60 -second three-point shooting test; FT\% $=$ free throw percentage during competitive season; FG $\%=$ field goal percentage during competitive season; $3 \mathrm{P} \%=$ three points field goal percentage during competitive season.

The multiple regression analyses were conducted to examine the relationship between physical fitness variables and the basketball shooting skill tests as the potential predictors and competitive shooting accuracy parameters as the dependent variables. Table 3 summarizes the analyses results. The results revealed that the physical fitness variables could not be used in prediction of the free-throws and field goals shooting accuracy during a competition. The exceptions is variable R-AvePOW that had significant positive correlation with the overall relationship with $\mathrm{FG} \%(\beta=.396, p=.039)$ indicating shooters with higher relative average anaerobic power to have better field goal percentage during a competition. CMJ jump height and SMBT distance had significant positive regression weights indicating players with better explosive power of lower and upper limbs to have better three-point shooting accuracy $(3 \mathrm{P} \%)$ during a competition $(\beta=.357, p=.037 ; \beta=.376, p=.044)$. The basketball shooting skill tests had significant influence in predicting the competitive shooting accuracy with higher contribution of the dynamic shooting tests compared to the stationary tests.

\section{Discussion}

This is one of the first studies that has investigated the association between basketball players' physical fitness, shooting skills and competitive shooting accuracy. The main finding of this research was firstly the existence of a positive relationship between basketball shooting skill tests, especially dynamic ones, and competitive shooting accuracy; and secondly, weak or no relationship between physical fitness and competitive shooting accuracy in a homogenous group of basketball perimeter players.

The results of this study show that shooting accuracy during a season can be predicted by applied shooting skill tests. The free throw skill tests, both dynamic and stationary, positively contributed to free throw shooting accuracy during the competitive season. However, it is very important to emphasize a higher contribution of the dynamic free throw test to competitive accuracy compared to the stationary test. On the other hand, there was no significant relationship between the stationary two-point shooting test and competitive field goal shooting accuracy. The dynamic 60 -second two-point shooting test significantly contributed to the field goal percentage during the competitive season. A similar positive relationship was obtained between the dynamic 60 -second three-point shooting test and the competitive three-point shooting percentage.

Therefore the evidence suggests that players who achieved a higher shooting percentage in the dynamic tests were more accurate during the season. We can assume that more accurate shooters were those who were more capable of coping with the fatigue produced in the sixty seconds of the dynamic tests. This ability probably helped them to cope with the competiti- 
ve fatigue as well and to be more accurate during the games. The fatigue induced during the dynamic tests can be explained by constructing tests that are structurally and physically very demanding, continuously requiring players to accelerate and decelerate, overcoming their body inertia. In other words, we can say that the dynamic tests are very similar to real competitive shooting situations when players need to stop and perform jump shots after having been sprinting in quick changes of direction. On the other hand, the applied shooting tests failed to integrate some parameters that could represent more realistic game shooting situations, such as the presence of an opponent, dribbling before shooting and competitive anxiety.

Unlike the shooting skill tests, physical fitness tests showed a lower prediction power of competitive shooting accuracy. No variable for the assessment of physical fitness has contributed to the prediction of free throw shooting accuracy. There are only three independent variables that contributed to the explanation of shooting accuracy. Jumping and throwing abilities influenced the results of three-point accuracy, while the field goal accuracy was determined by anaerobic capacities.

The power tests did not predict free throw and field gold percentage during a season, which suggests that they are weak predictors in shooting from shorter distances. The results showed the vertical jump performance to be the only good determinant of the three-point shooting percentage during the competitive season, i.e. players with higher CMJ height had a better three point shooting accuracy during the season. Its importance for precise shooting in a game is highlighted by Hudson (1982) who reported that more accurate shooters have a greater height of ball release. One of the factors that allowed the player to release the ball from a greater height was his/her ability to jump higher. This is particularly important during a game. A greater jump height enables a shooter to release the ball from a higher point which makes it difficult for the defender to block a shot, or to cover the target. This is in line with Sallet, Perrier, Ferret, Vitelli, and Baverel (2005) who suggests that when shooting over opponents, players try to release the ball more quickly and from a greater height. Moreover, a player's ability to jump higher enables them to disrupt the timing of a defending player and to establish more easily an advantageous shooting position (Hay, 1973; Miura, Yamamoto, Tamaki, \& Zushi, 2010). Furthermore, we can speculate that players with a higher ball release point are more self-confident and consequently more accurate as they know that defensive players are unlikely to block their shots. Results of the present study support the thesis by Delextrat and Cohen (2008), Hoffman, Epstein, Einbinder, and Weinstein (1999), and Hoffman et al. (1996) who suggested jumping ability as a key factor of basketball success.

The seated medicine ball toss test had a positive influence on competitive three-point accuracy as well. Our results suggest that the explosive power of the upper limbs is a good predictor when shots are performed from longer distances. The players with a longer medicine ball toss had a better three point shooting accuracy during the season as well. This is to some extent in accordance with the results of Tang and Shung (2005) who reported a significant correlation between long distance $(6.75 \mathrm{~m})$ shooting accuracy and elbow extensor isokinetic strength. In addition, Justin, Strojnik, and Šarabon (2006) reported that training for maximum strength of the elbow extensors improved the accuracy of three-point shooting. In this regard, players with less developed upper limb strength and power would probably activate some additional muscle groups and make compensatory movements to achieve their desired shooting distance. This is particularly noticeable among younger players who do not have enough strength to shoot the ball over longer distances. According to Erčulj and Supej (2006), the additional muscle activation may negatively influence shooting technique and consequently impair shooting accuracy. This is particularly important for shooting over longer distances and in conditions of fatigue (Erčulj \& Supej, 2006, 2009).

The field goal percentage during the season could be predicted by the measurements of the RAST parameters. This result indicates that the players who achieved larger relative average power and had higher anaerobic fatigue resistance had a higher field goal percentage. This is in accordance with the well-known fact that anaerobic capacities are very important in intensive activities that last between 30 and 90 seconds (Delextrat \& Cohen, 2008; Maud \& Foster, 2006) which is approximately the time duration of one live time basketball bout. We can speculate that players who achieved a bigger relative average power output were able to move down the basketball court more efficiently and consistently to easily make advantageous, undisturbed shooting positions for themselves. The influence of anaerobic capacities on shooting accuracy can be explained in light of fatigue resistance. It has been reported that moderate and high fatigue could negatively influence a jump shoot height and some other variables of shooting technique with shots performed over longer distances (Erčulj \& Supej, 2009). The players with higher levels of anaerobic capacities were more capable in coping with the negative effects of fatigue during repeated bouts of high intensity intermittent activities and had more chances to shoot with a proper technique, which is one of the determinants of greater accuracy.

Even though it was reported that aerobic power affects game performance (Ben Abdelkrim et al., 2006; Ben Abdelkrim et al., 2010; Castagna et al., 2008), in this study it has not been shown to be a good predictor of shooting accuracy. This is probably due to fact that the players are very homogenous in aerobic power. According to the results, it can be concluded that anaerobic power and capacities were better determinants of shooting accuracy than aerobic power. These results are in line with the findings of Hoffman et al. (1996) who reported that basketball success is more dependent on anaerobic power and capacities than on aerobic power. Additionally, speed, agility and upper limb muscular endurance have not been shown as good determinants of competitive shooting accuracy, although they are thought to be important for successful basketball playing (Delextrat \& Cohen, 2008; Hoare, 2000; Latin, Berg \& Baechle, 1994; Ostojić, Mazić \& Dikić, 2006; Sallet et al., 2005; Chaouachi et al., 2009). This can be a result of the low intersubject variability, or the homogeneity of the sample.

This study also provides performance data for basketball players as well as normative data for basketball shooting skill tests. When comparing this performance data with some ob- 
tained in previous investigations (Ben Abdelkrim et al., 2006; Castagna, Chaouachi, Rampinini, Chamari, \& Impellizzeri, 2009; Chaouachi et al., 2009; Ostojić et al., 2006), the results were worse, which can be attributed to a lower, national level of playing, rather than those playing at international level. This shows the need for further studies with designs that would include top level players. According to a known seasonal variation in physical fitness level and for stronger methodology, performance testing more than once during the season would be more appropriate, although we assumed that fitness levels would be at the highest at the end of season, or at least they would be under the same progress among players from the same team. Moreover, this study was conducted when a three-point line was at $6.25 \mathrm{~m}$, so a new investigation with the distance set at $6.75 \mathrm{~m}$ could be implemented. Other limitations included non-measurement of heart rate and blood lactates across the dynamic shooting tests which could help in explaining physiological response during the tests in order to facilitate better understanding of the induced fatigue.

\section{Conclusion}

According to the results, we can conclude that the overall relationship of the predictor variables with the shooting accuracy parameters was very small, which indicates that additional independent variables such cognitive and coordination measures should be used in order to explain the higher variance in shooting percentages during the season. However, the shooting skill tests, especially the dynamic ones, were shown to be better determinants of shooting accuracy during the season compared to the physical fitness. Only the power tests showed to be good predictors for shooting over longer distances.

Although the contribution of the dynamic tests to the relationship with the competitive accuracy parameters is relatively small, it can be said that it is important, because the other physical fitness tests do not show any relationships, or show very small relationships. The major significance of the dynamic tests is their application in assessing shooting accuracy of homogenous groups of basketball perimeter players when other fitness parameters cannot determine their competitive accuracy. Their application could be found in detecting talented basketball shooters.

In practice, the results can be very useful as they can help basketball and strength and conditioning coaches create better training programs to focus on overall explosive power development. Furthermore, the findings suggest an application of the dynamic shooting tests as an essential part of strength and conditioning programs to help players test, practice and improve their shooting accuracy in physically demanding conditions similar to those in a game. In this way players may become more resistant to specific fatigue and consequently more accurate during the competition.

\section{References}

Apostolidis, N., Nassis, G.P., Bolatoglou, T., \& Geladas, N.D. (2004). Physiological and technical characteristics of elite young baske- tball players. Journal of Sports Medicine and Physical Fitness, 44, 157-163.

Ben Abdelkrim, N., El Fazaa, S., \& El Ati, J. (2006). Time-motion analysis and physiological data of elite under-19-year-old basketball players during competition. British Journal of Sports Medicine, 41, 69-75.

Ben Abdelkrim, N., Chaouachi, A., Chamari, K., Chtara, M., \& Castagna, C. (2010). Positional role and competitive-level differences in elite-level men's basketball players. Journal of Strength and Conditioning Research, 24, 1346-1355.

Bosco, C., Luhtanen, P., \& Komi, P.V. (1983). A simple method for measurement of mechanical power in jumping. European Journal of Applied Physiology, 50, 273-282.

Castagna, C., Chaouachi, A., Rampinini, E., Chamari, K., \& Impellizzeri, F. (2009). Aerobic and explosive power performance of elite Italian regional-level basketball players. Journal of Strength and Conditioning Research, 23,1982-1987.

Castagna, C., Abt, G., Manzi, V., Annino, G., Padua, E., \& D’Ottavio S. (2008). Effect of recovery mode on repeated sprint ability in young basketball players. Journal of Strength and Conditioning Research, 22, 923-929.

Chaouachi, A., Brughelli, M., Chamari, K., Levin, G.T., Ben Abdelkrim, N., Laurencelle, L., \& Castagna, C. (2009). Lower limb maximal dynamic strength and agility determinants in elite basketball players Journal of Strength and Conditioning Research, 23, 1570-1577.

Delextrat, A., \& Cohen, D. (2008). Physiological testing of basketball players: toward a standard evaluation of anaerobic fitness. Journal of Strength and Conditioning Research, 22, 1066-1072.

Diener, M.H. Golding, A.L. \& Diener, D. (1995). Validity and reliability of a one-minute half sit-up test of abdominal strength and endurance. Sports Medicine, Training and Rehabilitation, 6, 105-119.

Erčulj, F., \& Supej, M. (2006). The impact of fatigue on jump shot height and accuracy over a longer shooting distance in basketball. Ugdym., Käuno kult, Sportas, 63, 35-41.

Erčulj, F., \& Supej, M. (2009). Impact of fatigue on the position of the release arm and shoulder girdle over a longer shooting distance for an elite basketball players. Journal of Strength and Conditioning Research, 23, 1029-1036.

Hashim, A. (2012). Objectivity, reliability, and validity of the $90^{\circ}$ push -ups test protocol among male and female students of sports science program. Journal of Physical Education and Sport, 12, 103-106.

Hay, J.G. (1973). The Biomechanics of Sports Techniques. Englewood Cliffs, NJ: Prentice Hall.

Hoare, D.G. (2000). Predicting success in junior elite basketball players: the contribution of anthropometric and physiological attributes. Journal of Science and Medicine in Sport, 3, 391-405.

Hoffman, J.R., Tenenbaum, G., Maresh, C.M., \& Kraemer, W.J. (1996). Relationship between athletic performance tests and playing time in elite college basketball players. Journal of Strength and Conditioning Research, 10, 67-71.

Hoffman, J.R., Epstein, S., Einbinder, M., \& Weinstein, Y. (1999). The influence of aerobic capacity on anaerobic performance and recovery indices in basketball players. Journal of Strength and Conditioning Research, 13, 407-411.

Hudson, J.L. (1982). A biomechanical analysis by skill level of free throw shooting in basketball. In: J. Terauds (Ed.), Biomechanics in Sports (95-102). Del Mar, CA: Academic Publisher.

Justin, I., Strojnik, V., \& Šarabon, N. (2006). Impact of increased maximum strength of elbow extensors on the precision of dart throws and three-point basketball shots. Sport, 2, 51-55.

Latin, R., Berg, K., \& Baechle, T. (1994). Physical and performance characteristics of NCAA division I male basketball players. Journal of Strength and Conditioning Research, 8, 214-218. 
Leger, L., \& Gadoury, C. (1989). Validity of the $20 \mathrm{~m}$ shuttle run test with 1 minute stages to predict VO2max in adults. Canadian Journal of Sport Science, 14, 21-26.

Lockie, R.G., Schultz, A.B., Callaghan, S.J., Jeffriess, M.D., \& Berry, S.P. (2013). Reliability and validity of a new test of change-ofdirection speed for field-based sports: the change-of-direction and acceleration test (CODAT). Journal of Sports Science and Medicine, 12, 88-96.

Markovic, G., Dizdar, D., Jukic, I., \& Cardinale, M. (2004). Reliability and factorial validity of squat and countermovement jump tests. Journal of Strength and Conditioning Research, 18, 551-555.

Maud, P.J., \& Foster, C. (2006). Physiology Assessment of Human Fitness ( $2^{\text {nd }}$ ed.) Champaign, IL: Human Kinetics.

McInnes, S.E., Carlson, J.S., Jones, C.J., \& McKenna, M.J. (1995). The physiological load imposed on basketball players during competition. Journal of Sport Science, 13, 387-97.

Miura, K., Yamamoto, M., Tamaki, H., \& Zushi, K. (2010). Determinants of the abilities to jump higher and shorten the contact time in running 1-leg vertical jump in basketball. Journal of Strength and Conditioning Research, 24, 201-206.

Narazaki, K., Berg, K., \& Stergiou, N. (2008). Physiological demands of competitive basketball Scandinavian Journal of Medicine and Science in Sports, Epub Apr.

Ostojić, S.M., Mazić, S., \& Dikić, N. (2006). Profiling in basketball: Physical and physiological characteristics of elite players Journal of Strength and Conditioning Research, 20, 740-744.

Pauole, K., Madole, K.. Garhammer, J., Lacourse, M., \& Rozenek, R. (2000). Reliability and Validity of the T-test as a measure of agility, leg power, and leg speed on college-aged men and women. Journal of Strength and Conditioning Research, 14, 443-450.

Pojskić, H., Šeparović, V., \& Užičanin, E. (2009). Differences between successful and unsuccessful basketball teams on the final Olympic tournament. Acta Kinesiologica, 3, 110-114.

Pojskić, H., Šeparović, V., \& Užičanin, E. (2011). Reliability and factorial validity of basketball shooting accuracy tests. Sport Scientific and Practical Aspects, 8, 25-32.

Sallet, P., Perrier, D., Ferret, J.M., Vitelli, V., \& Baverel, G. (2005). Physiological differences in professional basketball players as a function of playing position and level of play. Journal of Sports Medicine and Physical Fitness, 45, 291-294.

Semenick, D. (1990). The T-Test. NSCA J 12, 36-37.

Strand, B., \& Wilson, R. (1993). Assessing Sport Skills. Champaign, IL: Human Kinetics.

Tang, W.T., \& Shung, H.M. (2005). Relationship between isokinetic strength and shooting accuracy at different shooting ranges in Taiwanese elite high school basketball players Isokinetics and Exercise Science, 13, 169-174.

Tessitore, A., Tiberi, M., and Cortis C., Rapisarda, E., Meeusen, R., \& Capranica, L. (2006). Aerobic-anaerobic profiles, heart rate and match analysis in old basketball players. Gerontology, 52, 214-22.

Trninić, S., Dizdar, D., \& Lukšić, E. (2002). Differences between winning and defeated top quality basketball teams in final tournaments of European club championship. Collegium Antropologicum, 26, 521-531.

van den Tillaar, R. \& Marques, M.C. (2013). Reliability of seated and standing throwing velocity using differently weighted medicine balls. Journal of Strength and Conditioning Research, 27, 1234-1238.

WMADH. (2000). World Medical Association Declaration of Helsinki: Ethical principles for medical research involving human subjects. Journal of the American Medical Association, 284, 3043-3045.
Zagatto, A.M., Beck, W.R. \& Gobatto, C.A. (2009).Validity of the running anaerobic sprint test for assessing anaerobic power and predicting short-distance performances. Journal of Strength and Conditioning Research, 23, 1820-1827.

\section{Authors' note}

Haris Pojskić, Vlatko Šeparovic, Melika Muratović and Edin Užičanin are affiliated with School of Physical Education and Sport, University of Tuzla, Bosnia and Herzegovina. Haris Pojskić, Melika Muratović and Edin Užicanin are also affiliated with the Center for Sport Excellence, Tuzla, Bosnia and Herzegovina.

The study is part of a doctoral dissertation entitled: "Modelling competitive precision of basketball players based on certain anthropological dimensions"

\section{Acknowledgments}

This study was supported by the Federal Ministry of Education and Science of Bosnia and Herzegovina and by the Canton Ministry of Education, Science, Culture and Sport of Tuzla's Canton. The authors would like to thank the players and coaches from four Bosnian basketball teams (Čelik-Zenica, Sloboda-Tuzla, Student-Tuzla, FalconsTuzla) for their participation in the study. We would also like to thank Tuzla University's School of Physical Education and Sport as well as the faculty staff for their assistance in performing this study. Also, we would like to thank the management of the journal "Sport Scientific and Practical Aspects" for allowing the authors to use the modified figures in this article that previously was published in Vol.8, Issue 1.

\section{Corresponding author}

Haris Pojskić, Ph.D.

School of Physical Education and Sport, University of Tuzla.

2.oktobra 1, 75000 Tuzla, Bosnia and Herzegovina

Telephone: +387 (35) 278536

Fax: +351 (35) 278536

E-mail: haris.pojskic@untz.ba

Manuscript submitted on April 14, 2014

Manuscript accepted on September 20, 2014

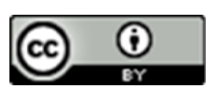

Motriz. The Journal of Physical Education. UNESP. Rio Claro, SP, Brazil - eISSN: 1980-6574 - under a license Creative Commons - Version 3.0 